\title{
Alterations in Pulmonary Diffusing Capacity and Pulmonary Capillary Blood Volume with Negative Pressure Breathing *
}

\author{
Sheldon H. Steiner, $\nmid$ Regina Frayser, and Joseph C. Ross $\ddagger$ \\ (From the Medical Service, Veterans Administration Hospital, the Department of Medicine \\ and the Heart Research Center, Indiana University Medical Center, \\ Indianapolis, Ind.)
}

In $1915 \mathrm{Krogh}$ first reported that the breathholding pulmonary diffusing capacity for carbon monoxide (DL) is increased during exercise (1). Although change in the volume of blood in the pulmonary capillary bed $(\mathrm{Vc})$, as determined by change in DL, can be produced by several mechanisms, it is during exercise that the greatest changes are observed. Yet, in a previous investigation in which some of the physiologic changes of exercise were simulated, such as alterations in alveolar ventilation, alveolar volume, cardiac output, mixed venous $\mathrm{PCO}_{2}$, and mixed venous $\mathrm{Po}_{2}$, there was little change in breath-holding DL (2).

Rosenberg and Forster (3), studying isolated cat lungs, concluded that the pressure across the walls of the pulmonary blood vessels is a primary factor in controlling the size of the pulmonary capillary bed as measured by DL. Observations by other investigators have agreed with this hypothesis (4). Breath-holding DL is increased by central venous engorgement with elevated pulmonary vascular pressure induced by pressure suit inflation $(2,5,6)$. In addition, changes in gravitational orientation from the supine to erect position result in a small decrease in $\mathrm{DL}$ and $\mathrm{Vc}(7)$, which can be prevented by pressure suit inflation.

Head-down tilt increases right atrial pressure and also increases $\mathrm{DL}_{\mathrm{L}}$ and $\mathrm{Vc}$ (8). Atropine diminishes central venous pressure $(9,10)$ and pulmonary blood volume and decreases $\mathrm{DL}_{\mathrm{L}}$ and $\mathrm{Vc}$ in

\footnotetext{
* Submitted for publication February 8, 1965; accepted June 18, 1965.

Supported by research grants HE-6308, HE-7398, and HE-6228 from the National Heart Institute and by U. S. Air Force contract 33(616)8378.

† Veterans Administration Clinical Investigator.

$\ddagger$ Address requests for reprints to Dr. Joseph C. Ross, Indiana University Medical Center, $1100 \mathrm{~W}$. Michigan St.., Indianapolis, Ind. 46207.
}

the seated as well as the supine position. Positive pressure breathing has similar effects, and atropine and positive pressure breathing synergistically decrease breath-holding $\mathrm{DL}_{\mathrm{L}}$ and Vc (11).

In view of these previous findings, it seemed likely that a negative intra-alveolar pressure should increase Vc and, therefore, DL by an increased filling of the capillaries resulting from the negative pressure, possibly due to an increase in effective distending pressure of the pulmonary capillary bed. Some previous studies, however, do not necessarily agree with this conclusion. Cotes, Snidal, and Shepard (12), in only two subjects, found variable effects of negative intra-alveolar pressure on DL and Vc. Arterial blood oxyhemoglobin desaturation occurs during negative pressure breathing (13), and an increase in DL has not been reported to occur concomitantly with a decrease in arterial blood oxygen saturation. During negative pressure breathing the mechanical properties of the lung and thorax are such that it has been equated to forward acceleration induced in a human centrifuge (radial acceleration vector from back to chest) (14). Significant arterial blood oxygen desaturation, incompletely corrected by oxygen therapy, also occurs during forward acceleration (15), and the pulmonary diffusing capacity is diminished (16). This analogy to forward acceleration makes it somewhat difficult to predict what might be the exact nature of the response of the pulmonary capillary bed to negative pressure breathing.

This investigation was designed to define more completely the effects of negative pressure breathing on the pulmonary capillary bed.

\section{Methods}

Subjects. Twelve previously trained, normal males 22 to 36 years old served as experimental subjects. They 
were in the postabsorptive state and rested 30 to $45 \mathrm{~min}$ utes before the experimental procedure. Three separate studies were required to complete the measurements of DL, Vc, and oxygen consumption at intra-alveolar pressures of -26 and $-52 \mathrm{~cm}$ water. Not all the subjects completed the entire protocol, and replicate determinations were made in several.

Experimental conditions. All measurements were made with the subject in the seated position. During the last 5 minutes of the rest period the noseclip and mouthpiece were put in place. No effort was made to control respiratory frequency, tidal volume, or functional residual capacity. The subjects were carefully instructed to maintain an open glottis at all times.

Duplicate control measurements of breath-holding DL were made. The apparatus was then placed under reduced pressure, and the measurements were repeated at the end of 4 and 7 minutes of continuous full-phase negative pressure breathing and 3 minutes after termination of the 7-minute negative pressure breathing period. This time was chosen arbitrarily since $D_{L}$ is usually back to normal 3 minutes after termination of exercise. No attempt was made to follow the time course of the return of DL to normal after negative pressure breathing. The closed circuit apparatus consisted of a 50-gallon drum, connected to a vacuum source, in series with a $\mathrm{CO}_{2}$ absorber and a Krogh respiratory valve. A Donald-

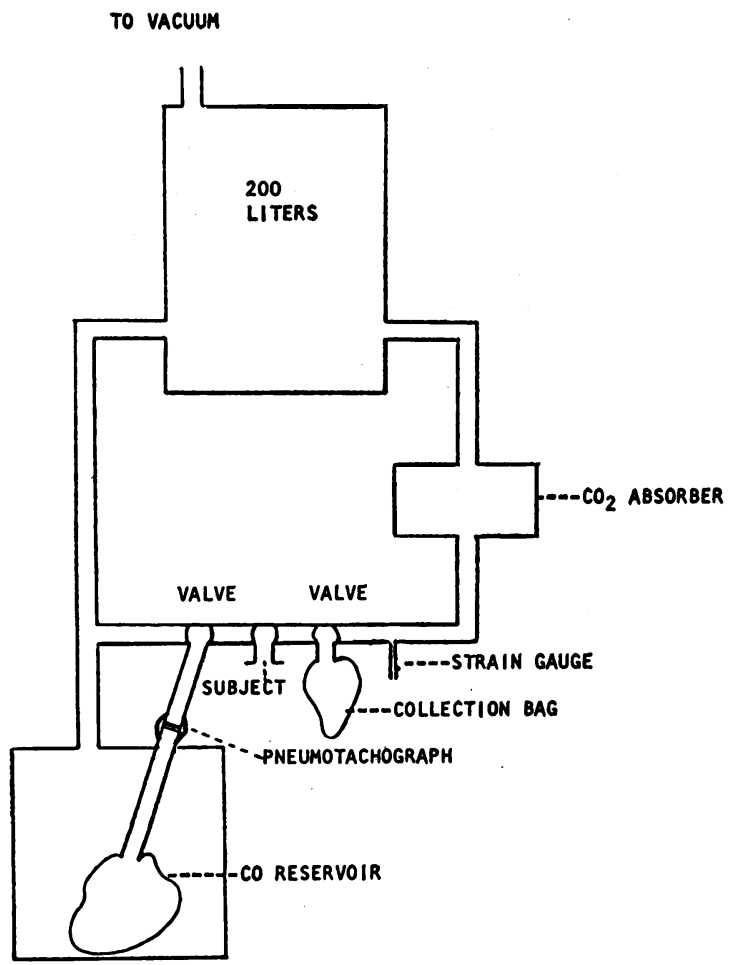

Fig. 1. Apparatus USEd to measure pUlmonary DIFFUSING CAPACITY (DL) AND INSTANTANEOUS PULMONARY CAPILLARY BLOOD VOLUME (VC) DURING NEGATIVE PRESSURE BREATHING.

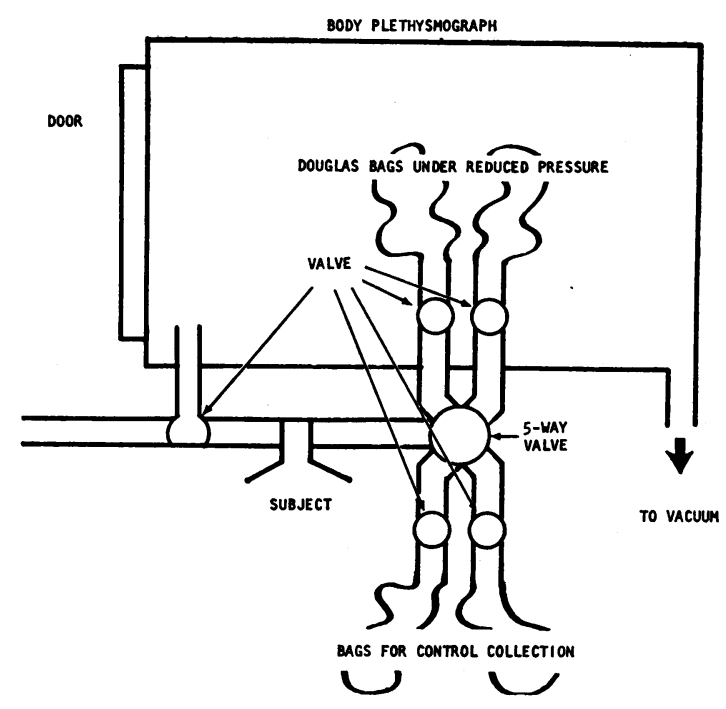

Fig. 2. Open circuit apparatus USED to MEASURE OXYGEN CONSUMPTION DURING NEGATIVE PRESSURE BREATHING.

Christie box containing the carbon monoxide, neon, oxygen mixture was connected in parallel so that it was also under reduced pressure during the experimental procedure, as shown in Figure 1. The beginning of inspiration during the breath-holding maneuver, breath-holding time, and the inspiratory volume was determined with a calibrated pneumotachograph coupled to an integrating amplifier and electronically recorded. The beginning of expiration was defined from the output of a pressure gauge inserted into the expiratory line. This entire procedure was carried out in every subject with a pressure of $-26 \mathrm{~cm} \mathrm{H}_{2} \mathrm{O}$ and with $0.4 \% \mathrm{CO}, 1.0 \%$ neon, $21 \%$ $\mathrm{O}_{2}$ in nitrogen as the inspired gas mixture used to determine DL. The procedure was repeated at $-52 \mathrm{~cm}$ $\mathrm{H}_{2} \mathrm{O}$ pressure with the same gas mixture. For calculation of $\mathrm{Vc}$ in five subjects, the procedure was repeated at $-26 \mathrm{~cm} \mathrm{H}_{2} \mathrm{O}$ pressure with $0.4 \% \mathrm{CO}$ and $1.0 \%$ neon in oxygen as the gas mixture for $\mathrm{DL}_{\mathrm{L}}$ determination, and in four of these subjects, it was repeated at $-52 \mathrm{~cm} \mathrm{H}_{2} \mathrm{O}$ pressure with the same gas mixture.

Oxygen consumption was measured by an open-system technique. A body plethysmograph was used as the negative transpulmonary pressure reservoir and was adjusted to proper pressure by a vacuum pump. The subject was at ambient pressure outside of the chamber and was connected to it through a carefully sealed Krogh valve and a five-way Rudolph valve by low resistance respiratory tubing that passed through the chamber wall by means of metal nipples. The expiratory side re-entered the box and was connected to $100-\mathrm{L}$ Douglas bags as shown in Figure 2. Duplicate control measurements were made over 3 -minute collection periods, and $5 \mathrm{~min}$ utes was allowed between these measurements. During the 7-minute period of pressure breathing, expired air was collected in one bag for 4 minutes and then in a second bag for the last 3 minutes. At the end of an 
experimental period all expired gas was collected for the next 9 minutes in three equal periods. Ventilatory rate was monitored by a pneumograph and was recorded electronically. At least 30 minutes was allowed for recovery between all procedures.

Calculation of breath-holding diffusing capacity and pulmonary capillary blood volume. DL was determined by the Krogh breath-holding technique as modified by Ogilvie, Forster, Blakemore, and Morton (17) and as previously reported from this laboratory using a gas chromatograph to analyze alveolar samples for neon, carbon monoxide, carbon dioxide, and oxygen concentrations (18). The alveolar volume (VA) was calculated from inspired and expired alveolar neon concentrations (Ner, $\mathrm{NeA}$ ) and inspired volume (VI).

$$
\mathrm{VA}_{\mathbf{A}}=\frac{\mathrm{NeI}}{\mathrm{NeA}} \times \mathrm{VI}_{\mathbf{A T P S}}
$$

$\mathrm{V}_{\text {ASTPD }}=\mathrm{V}_{\text {A }}$ ATPS $\times$ temperature correction factor. (ATPS is ambient temperature and pressure, saturated with water; STPD is standard temperature and pressure, dry.) The dead space of the apparatus used for both control and negative pressure measurements was constant, less than $100 \mathrm{ml}$, and was included in the calculation of VA. In the formula for calculation of $\mathrm{DL}$,

DL (milliliters $\mathrm{CO}_{\text {STPD }}$ per minute per millimeter $\mathrm{Hg} \mathrm{CO}$ )

$$
=\frac{\left(V_{A}\right)(60)}{(t)\left(P_{B}-47\right)} \times \ln \frac{F_{A C O_{0}}}{F_{A C O t}}
$$

(where $\mathrm{PB}_{\mathrm{B}}$ is barometric pressure, $\mathrm{t}$ is time in seconds, and $\mathrm{FACO}_{\mathrm{O}}$ and $\mathrm{FACO}_{\mathrm{t}}$ are the initial and final $\mathrm{CO}$ concentrations in the expired alveolar sample), correction was made for pressure during negative pressure breathing as follows: at $-26 \mathrm{~cm}$ water $\left(\mathrm{P}_{\mathrm{b}}-20-47\right)$, and at $-52 \mathrm{~cm}$ water $\left(P_{b}-40-47\right)$.

Vc was calculated by the method of Roughton and Forster (19) using measurements of $\mathrm{Di}$ at two different alveolar $\mathrm{O}_{2}$ tensions under each condition and assuming 2.5 as the ratio of permeability of the red cell membrane to that of its interior. The absolute alveolar $\mathrm{O}_{2}$ tension at which each determination was made was known from alveolar sample analysis. Mean capillary $\mathrm{O}_{2}$ tension was then estimated according to the method of $\mathrm{McNeill}$, Rankin, and Forster (20). $\theta$ for the appropriate $\mathrm{O}_{2}$ tension was obtained from the data of Roughton, Forster, and Cander (21). The values for $\theta$ were calculated with an assumed $C O$ capacity of $20 \mathrm{ml}$ per $100 \mathrm{ml}$ blood. Since each subject served as his own control and $\mathrm{O}_{2}$ capacity is not greatly altered during negative pressure breathing (12), no correction was made for variations in $\mathrm{CO}$ capacity.

The oxygen cost of the added work of negative pressure breathing. Oxygen consumption and carbon dioxide excretion were measured as previously outlined with an open-circuit collecting system. The fractional concentrations of oxygen and carbon dioxide in expired air were measured, respectively, in a paramagnetic oxygen analyzer and an infrared carbon dioxide analyzer. The volume of expired air was measured in a gas meter. The volume inspired was calculated from the expired volume as follows :

$$
\mathrm{VI}=\mathrm{VE} \frac{1-\mathrm{FE}_{\mathrm{O}_{2}}-\mathrm{FE}_{\mathrm{CO}_{2}}}{1-\mathrm{FI}_{\mathrm{O}_{2}}}
$$

where $V_{I}$ and $V_{E}$ are inspired and expired volumes and $\mathrm{FE}_{\mathrm{O}_{2}}, \mathrm{FE}_{\mathrm{CO}_{2}}$, and $\mathrm{F}_{\mathrm{IO}_{2}}$ are the fractional concentrations of oxygen and carbon dioxide in expired and inspired air. Oxygen consumption and carbon dioxide excretion were calculated in the usual manner and are reported at STPD. Minute ventilation and tidal volume are reported at BTPS (body temperature and pressure, saturated with water) with appropriate correction for the difference in gas volumes resulting from the reduction in ambient pressure during the experimental breathing periods. The additional oxygen consumed during pressure breathing was determined by assuming that the pre-experimental control oxygen consumption represented the base-line value for the subsequent period.

\begin{tabular}{|c|c|c|c|c|c|c|c|c|c|c|c|c|c|c|c|c|}
\hline & \multicolumn{8}{|c|}{$-26 \mathrm{~cm}$} & \multicolumn{8}{|c|}{$-52 \mathrm{~cm}$} \\
\hline & \multicolumn{2}{|c|}{ Control } & \multicolumn{2}{|c|}{4 minutes } & \multicolumn{2}{|c|}{7 minutes } & \multicolumn{2}{|c|}{ Post 3 minutes } & \multicolumn{2}{|c|}{ Control } & \multicolumn{2}{|c|}{4 minutes } & \multicolumn{2}{|c|}{7 minutes } & \multicolumn{2}{|c|}{ Post 3 minutes } \\
\hline & $\mathrm{DL}^{*}$ & VAt & DL & $\mathrm{V}_{\mathbf{A}}$ & DL & $\mathbf{V A}_{\mathbf{A}}$ & DL & $V_{A}$ & DL & VA & DL & $\mathbf{V}_{\mathbf{A}}$ & $D_{\mathbf{L}}$ & $\mathbf{V}_{\mathbf{A}}$ & $\mathrm{DL}$ & $\mathbf{V}_{\mathbf{A}}$ \\
\hline S.S. & 31.1 & 4.42 & 45.5 & 5.44 & 49 & 5.03 & 36.3 & 5.28 & 31.1 & 4.42 & 46.5 & 4.94 & 37.5 & 4.23 & 36.8 & 4.33 \\
\hline R.D. & 43.2 & 3.85 & 54.0 & 5.27 & 74.8 & 5.48 & 40.7 & 4.71 & 43.9 & 4.41 & 42.7 & 3.71 & 49.0 & 3.63 & 50.4 & 4.61 \\
\hline J.R. & 38.8 & 5.97 & 50.7 & 6.64 & 46.9 & 6.95 & 39.2 & 6.19 & 36.7 & 5.86 & 45.9 & 6.41 & 41.3 & 6.41 & 43.2 & 6.92 \\
\hline C.D. & 30.1 & 5.34 & 39.5 & 5.70 & 34.9 & 5.54 & 31.7 & 5.86 & 31.4 & 5.58 & 44.1 & 4.99 & 41.8 & 4.80 & 35.4 & 5.97 \\
\hline N.V.R. & 39.4 & 5.05 & 51.5 & 5.30 & 69.2 & 5.50 & 57.0 & 4.90 & 32.1 & 4.80 & 41.8 & 3.05 & 36.6 & 3.56 & 34.5 & 3.38 \\
\hline M.L. & 43.7 & 5.42 & 57.0 & 5.95 & 49.8 & 5.38 & 38.4 & 4.99 & 39.0 & 4.15 & 59.7 & 5.09 & 65.9 & 5.06 & 45.2 & 5.58 \\
\hline J.O. & 30.9 & 4.36 & 37.6 & 4.65 & 32.1 & 4.58 & 34.1 & 5.10 & 28.4 & 3.96 & 53.1 & 4.46 & 50.6 & 4.29 & 27.3 & 4.26 \\
\hline L.D. & 37.8 & 6.48 & 43.6 & 7.04 & 41.0 & 6.80 & 37.1 & 6.91 & & & & & & & & \\
\hline Mean & 36.9 & 5.11 & 47.4 & 5.75 & 49.7 & 5.66 & 39.2 & 5.49 & 34.6 & 4.74 & 48.2 & 4.66 & 46.2 & 4.86 & 39.0 & 4.98 \\
\hline SD & \pm 5.2 & \pm .82 & \pm 6.5 & \pm .73 & \pm 11.4 & \pm .76 & \pm 7.2 & \pm .71 & \pm 5.0 & \pm .67 & \pm 5.9 & \pm .98 & \pm 9.4 & \pm .94 & \pm 7.2 & \pm 1.07 \\
\hline p & & & $<.01$ & $<.01$ & $<.005$ & $<.05$ & NS & NS & & & $<.005$ & NS & $<.005$ & NS & $<.025$ & NS \\
\hline
\end{tabular}

TABLE I

Pulmonary diffusing capacity $\left(D_{L}\right)$ and alveolar volume $\left(V_{A}\right)$ during negative pressure breathing

* $\mathrm{DL}_{\mathrm{L}}=$ milliliters $\mathrm{CO}$ per minute per millimeter $\mathrm{Hg}$.

$+\mathrm{V}_{\mathbf{A}}=$ liters per breath. 
TABLE II

Pulmonary capillary blood volume $(V c)$ during negative pressure breathing

\begin{tabular}{|c|c|c|c|c|c|c|c|c|}
\hline & \multicolumn{4}{|c|}{$-26 \mathrm{~cm}$} & \multicolumn{4}{|c|}{$-52 \mathrm{~cm}$} \\
\hline & Control & 4 minutes & 7 minutes & $\begin{array}{c}\text { Post 3 } \\
\text { minutes }\end{array}$ & Control & 4 minutes & 7 minutes & $\begin{array}{c}\text { Post 3 } \\
\text { minutes }\end{array}$ \\
\hline & \multicolumn{4}{|c|}{$m l$} & \multicolumn{4}{|c|}{$m l$} \\
\hline $\begin{array}{l}\text { S.S. } \\
\text { R.D. } \\
\text { N.V.R. } \\
\text { J.O. } \\
\text { L.D. }\end{array}$ & $\begin{array}{r}77 \\
100 \\
98 \\
68 \\
120\end{array}$ & $\begin{array}{r}97 \\
90 \\
\\
79 \\
130\end{array}$ & $\begin{array}{r}118 \\
90 \\
143 \\
93 \\
135\end{array}$ & $\begin{array}{r}87 \\
94 \\
110 \\
68 \\
115\end{array}$ & $\begin{array}{r}89 \\
96 \\
110 \\
72\end{array}$ & $\begin{array}{r}100 \\
100 \\
157 \\
94\end{array}$ & $\begin{array}{r}102 \\
108 \\
125 \\
96\end{array}$ & $\begin{array}{r}79 \\
104 \\
91 \\
80\end{array}$ \\
\hline $\begin{array}{l}\text { Mean } \\
\text { SD } \\
\text { p }\end{array}$ & $\begin{array}{r}93 \\
\pm 18\end{array}$ & $\begin{array}{r}99 \\
\pm 19 \\
\text { NS }\end{array}$ & $\begin{array}{r}116 \\
\pm 21 \\
<.05\end{array}$ & $\begin{array}{r}95 \\
\pm 17 \\
\text { NS }\end{array}$ & $\begin{array}{r}92 \\
\pm 14\end{array}$ & $\begin{array}{r}113 \\
\pm 26 \\
<.01\end{array}$ & $\begin{array}{r}108 \\
\pm 11 \\
<.05\end{array}$ & $\begin{array}{r}88 \\
\pm 10 \\
\text { NS }\end{array}$ \\
\hline
\end{tabular}

Statistical analysis. The data were analyzed by the method of paired comparisons with the Student $t$ test, each subject serving as his own control (22). Significance was determined at the $95 \%$ confidence level.

\section{Results}

Pulmonary diffusing capacity and capillary blood volume. DL was increased significantly after 4 and 7 minutes of continuous negative pressure breathing, both $-26 \mathrm{~cm} \mathrm{H}_{2} \mathrm{O}$ and $-52 \mathrm{~cm}$ $\mathrm{H}_{2} \mathrm{O}$, and returned to prepressure breathing control levels within 3 minutes after terminating -26 $\mathrm{cm} \mathrm{H}_{2} \mathrm{O}$ pressure breathing, but remained slightly elevated 3 minutes after terminating $-52 \mathrm{~cm} \mathrm{H}_{2} \mathrm{O}$ pressure breathing (Table $\mathrm{I}$ ). The differences in De between 4 and 7 minutes and -26 and -52 $\mathrm{cm} \mathrm{H}_{2} \mathrm{O}$ are not significant. $\mathrm{V}_{A}$ was increased slightly during negative pressure breathing at -26 $\mathrm{cm} \mathrm{H}_{2} \mathrm{O}$, but not enough to be a factor in causing the marked increase in DL. The reason for the increase in $\mathrm{VA}_{\mathrm{A}}$ is not known.

After 4 minutes of breathing against $-26 \mathrm{~cm}$ $\mathrm{H}_{2} \mathrm{O}$ continuous negative pressure, the observed increase in $\mathrm{Vc}$ was not significant. However, at 7 minutes Vc was significantly increased from the control level (Table II). With $-52 \mathrm{~cm} \mathrm{H}_{2} \mathrm{O}$ breathing, Vc was significantly increased at 4 minutes and at 7 minutes. $\mathrm{Vc}$ had returned to control levels within 3 minutes after negative pressure breathing.

Oxygen cost of negative pressure breathing. The exercise equivalent level of negative pressure breathing was assessed by the extent to which oxygen consumption increased. The results ob-

TABLE III

Oxygen consumption $\left(\dot{V}_{\mathrm{O}_{2}}\right)$, carbon dioxide excretion $\left(\dot{V}_{\mathrm{CO}_{2}}\right)$, the respiratory exchange ratio $\left(R_{E}\right)$, and minute ventilation $\left(\dot{V}_{E}\right)$ and tidal volume $(\dot{V} T)$ during negative pressure breathing

\begin{tabular}{|c|c|c|c|c|c|c|}
\hline & \multicolumn{3}{|c|}{$-26 \mathrm{~cm}$} & \multicolumn{3}{|c|}{$-52 \mathrm{~cm}$} \\
\hline & Control 1 & Control 2 & 5-7 minutes & Control 1 & Control 2 & 5-7 minutes \\
\hline$\dot{\mathrm{VO}}_{2}\left(m l_{\mathrm{STPD}}\right)$ & $\begin{array}{l}287 \\
\pm 37.9\end{array}$ & $\begin{array}{l}276 \\
\pm 46.6 \\
\text { NS }\end{array}$ & $\begin{array}{l}311 \\
\pm 35.2 \\
<.025\end{array}$ & $\begin{array}{c}304 \\
\pm 38.4\end{array}$ & $\begin{array}{c}298 \\
\pm 32.3 \\
\text { NS }\end{array}$ & $\begin{array}{c}348 \\
\pm 34.6 \\
<.01\end{array}$ \\
\hline $\begin{array}{r}\dot{\mathrm{V}} \mathrm{CO}_{2}\left(m l_{\mathrm{STPD}}\right) \\
\mathrm{SD} \\
\mathrm{p}\end{array}$ & $\begin{array}{c}248 \\
\pm 30.7\end{array}$ & $\begin{array}{l}253 \\
\pm 61.0 \\
\text { NS }\end{array}$ & $\begin{array}{l}309 \\
\pm 78.6 \\
<.01\end{array}$ & $\begin{array}{l}253 \\
\pm 48.3\end{array}$ & $\begin{array}{r}257 \\
\pm 52 \\
\mathrm{NS}\end{array}$ & $\begin{array}{l}334 \\
\pm 86 \\
<.005\end{array}$ \\
\hline RE $\quad$ SD & $\begin{array}{r}.87 \\
\pm .05\end{array}$ & $\begin{array}{l} \pm .92 \\
\mathrm{NS}\end{array}$ & $\begin{array}{l}.98 \\
\pm .15 \\
<.025\end{array}$ & $\begin{array}{r}.83 \\
\pm .08\end{array}$ & $\begin{array}{l}\begin{array}{r}.85 \\
\mathrm{NS}\end{array} \\
\mathrm{N}\end{array}$ & $\begin{array}{r}.94 \\
\pm .17 \\
<.01\end{array}$ \\
\hline$\dot{\mathrm{VE}}\left(L_{\mathrm{BTPS}}\right)_{\mathrm{SD}}$ & $\begin{aligned} & 8.88 \\
\pm & 2.6\end{aligned}$ & $\begin{array}{ll} & 8.83 \\
\pm & 2.8 \\
\mathrm{NS}\end{array}$ & $\begin{array}{c}12.02 \\
\pm 3.6 \\
<.05\end{array}$ & $\begin{array}{r}8.66 \\
\pm 2.02\end{array}$ & $\begin{array}{ll} & 8.87 \\
\pm & 1.8 \\
\mathrm{NS}\end{array}$ & $\begin{array}{l}11.45 \\
\pm 3.7 \\
<.05\end{array}$ \\
\hline VT $\left(m l_{\mathrm{BTPS}}\right)$ SD & $\begin{array}{r}792 \\
\pm 340\end{array}$ & $\begin{array}{r}800 \\
\pm 372 \\
\mathrm{NS}\end{array}$ & $\begin{array}{l}1,158 \\
\pm 617 \\
<.005\end{array}$ & $\begin{array}{r}848 \\
\pm 302\end{array}$ & $\begin{array}{r}853 \\
\pm 314 \\
\mathrm{NS}\end{array}$ & $\begin{array}{l}1,261 \\
\pm 477 \\
<.05\end{array}$ \\
\hline
\end{tabular}


tained for duplicate control measurements, shown in Table III, were averaged, since measurements taken 3 minutes apart were not statistically different. The additional oxygen consumed was statistically significant.

\section{Discussion}

This study gives further information about how the size of the pulmonary capillary bed can be changed. Continuous negative pressure breathing consistently increased breath-holding DL and Vc to values comparable to those demonstrated during moderately severe exercise (23). It seems reasonable that this increase should occur. Although there are some conflicting observations (24), most investigators have found an increase in thoracic blood volume during negative pressure breathing (25-27). Ernsting (26) reported a decrease in lung compliance during negative pressure breathing, which could be due to the increased amount of blood in the lung.

Unlike exercise, however, a substantial increase in energy expenditure does not occur, indicating that the increase in $D_{L}$ and $V c$ during negative pressure breathing is not due to the metabolic effects of muscular work.

DL increases as $\mathrm{O}_{2}$ tension decreases because of the change in the reaction rate of $\mathrm{CO}$ with hemoglobin (19). Negative intra-alveolar pressure can be expected to slightly diminish alveolar oxygen tension, and the decrease in peripheral arterial oxyhemoglobin saturation in man at $-52 \mathrm{~cm}$ water reported by Steiner and Behnke (13) is small (from $96.9 \%$ to $92.6 \%$ saturation). The associated decrease in tension is not sufficiently great to account for the large increase in DL.

Mean alveolar volume at which $\mathrm{DL}_{\mathrm{L}}$ was measured was significantly increased after 4 and 7 minutes of $-26 \mathrm{~cm} \mathrm{H} \mathrm{H}_{2} \mathrm{O}$ breathing. This is likely due to the difference in inspiratory effort between normal breathing and negative pressure breathing. Subjects were not required to take an absolutely maximal inspiration for DL measurement. The difference between mean control $\mathrm{VA}_{\mathrm{A}}$ and mean $\mathrm{VA}_{\mathrm{A}}$ at 4 minutes of $-26 \mathrm{~cm} \mathrm{H}_{2} \mathrm{O}$ breathing was .64 $\mathrm{L}$ and was the greatest increase observed. $\mathrm{DL}_{\mathrm{L}}$ does increase when the $\mathrm{VA}_{\mathrm{A}}$ at which it is measured increases, but in a previous study (28), a $40 \%$ increase in $V_{A}$ was associated with a $20 \%$ in- crease in DL. The small increase in VA in the present study, then, is not sufficient to be a factor in causing the large increase in DL observed. In addition, Ross and co-workers $(2,29)$ have reported that there is no significant effect upon DL of hyperventilation at rest or of controlled ventilation during exercise.

The findings in this study indicate that the increase in DL that occurs with negative pressure breathing is attributable to an increase in the size of the effectively ventilated pulmonary capillary bed $(\mathrm{Vc})$. As postulated for exercise, the increase in Vc may be due to distention of already open capillaries or opening of capillaries previously closed. Other investigators (12) have suggested that these changes might be due to an increased blood flow through the lungs, to an increased filling of the capillaries resulting from the negative pressure, or to an increased pressure gradient between the alveolar capillaries and the left atrium. It is conceivable that through any one of these three mechanisms, alterations in the distribution of perfusion could occur, leading to increase in the size of the effective pulmonary capillary bed by the addition of capillaries not previously perfused or ventilated. On the other hand, either of these mechanisms might also produce an increase in the size of the previously open capillaries.

Other investigators $(24,25,30)$ have shown that pulmonary blood flow is significantly increased during negative pressure breathing and, in the lung, upper zone perfusion is increased as blood flow goes up (31). Increasing cardiac output by techniques other than exercise, however, does not increase DL or, presumably, $V_{c}(2,32)$. This strongly suggests that the per se increase in pulmonary blood flow is not the mechanism by which DL and Vc are increased.

Normally, pulmonary vascular pressure is inadequate to sustain the necessary hydrostatic column to perfuse the apical zone in upright man $(31,33)$. During negative pressure breathing the observed increases in DL and Vc are considerably greater than can be accounted for solely by the abolition of the postural blood flow gradient (7). The recent report by West and Dollery (34) concerning the lack of a critical closing pressure phenomenon (35) in the pulmonary vascular bed indicates that perfusion bears a direct relation to the 
effective distending pressure. Holt (36), Ting, Hong, and Rahn (37), and Lenfant and Howell (30) reported that although central venous pressures decrease with negative pressure breathing, the effective distending pressures are considerably increased, since the vascular pressure drop is only about one-half of the fall in applied alveolar pressure. West, Dollery, and Naimark (38) using the clearance rate of oxygen ${ }^{15}$-labeled $\mathrm{CO}_{2}$ and Rosenberg and Forster (3) have concluded that the pressure across the walls of the pulmonary blood vessels is a primary factor in control of the size of the pulmonary capillary bed. Although the increase in Vc during negative pressure breathing must be due, at least in part, to more effective distribution of perfusion, it also seems certain that this is not the only way in which Vc is increased and that previously open capillaries are also being distended, probably as a mechanical consequence of the applied negative pressure.

Either some perfused alveoli also become less well ventilated, or direct capillary shunts are opened by the negative pressure, since a decrease in arterial oxygen saturation occurs during negative pressure breathing (13). In the dog, at least, the decreased arterial oxygen saturation during negative pressure breathing is not fully corrected by oxygen breathing, indicating the existence of direct pulmonary arteriovenous communications (30).

The findings of this study are interesting and important. The increases in DL reported here during negative pressure breathing are greater than have been produced by any technique other than active exercise. In a previous study (11), it was shown that DL and Vc are dependent on pulmonary vascular pressures, or volume, or both, and relatively independent of cardiac output. Positive pressure breathing decreases DL and Vc (11), but the changes in DL and $\mathrm{Vc}$ in the opposite direction during negative pressure breathing are of greater magnitude. This study gives further support to the concept that $\mathrm{Vc}$ is dependent on effective distending pressure and relatively independent of cardiac output.

There is a limit, however, to the relationship between distending pressure and the size of the effective pulmonary capillary bed. In this study, DL and $\mathrm{Vc}$ were not increased further with $-52 \mathrm{~cm}$ $\mathrm{H}_{2} \mathrm{O}$ pressure breathing in comparison with -26 $\mathrm{cm} \mathrm{H}_{2} \mathrm{O}$ pressure breathing. This agrees with the findings of a previous study in which the effective distending pressure was changed by increasing the central vascular pressure by head-down tilt or pressure suit inflation or both (8). Maximal DL increase occurred with an increase in right atrial pressure of about $7 \mathrm{~mm} \mathrm{Hg}$ and did not increase further despite large increases in central vascular pressure.

Since the increase in DL observed during negative pressure breathing is more comparable to that occurring with exercise than under any other circumstance, the question naturally arises as to whether negative intra-alveolar pressure plays any part in the increased DL and Vc during exercise or is associated with the breath-holding maneuver and responsible, at least in part, for DL determined by the breath-holding technique being higher than DL measured by the steady-state technique. Answering these questions is beyond the scope of this paper. It should be pointed out, however, that Mostyn and his colleagues (39) found that a 7 -second maximal breath-holding maneuver (similar to that required for measurement of breathholding $D_{L}$ ) during the measurement of steadystate DL with continuous exercise caused a further increase in DL and Vc. Intra-esophageal pressures were also measured and ranged from +12 to -20 $\mathrm{cm} \mathrm{H}_{2} \mathrm{O}$ during the held-breath maneuver. They concluded that the degree of lung inflation, not the pressures, during the held-breath maneuver accounted for the further increase in DL during exercise. Nevertheless, if their data for maximal values of inspiratory pressures during the inspiratory phase preceding the onset of breath holding ( -14 to $-100 \mathrm{~cm} \mathrm{H}_{2} \mathrm{O}$ ) are plotted against the steady-state measurement for $\mathrm{DL}_{L}$ in each subject, the result is a linear regression equation $(y=.44 x$ $+27.2 ; x=$ esophageal pressure in centimeters $\mathrm{H}_{2} \mathrm{O}$, and $y=\mathrm{DL}$ in milliliters $\mathrm{CO}$ per minute per millimeter $\mathrm{Hg}$ ) and a correlation coefficient of +96 . This definitely suggests that the mechanism may play some part in the difference between steady-state and breath-holding DL measurements and in the increase of DL during exercise.

\section{Summary}

Negative pressure breathing increases pulmonary capillary blood volume (Vc) and breath-hold- 
ing diffusing capacity for carbon monoxide (DL) to a degree comparable to that occurring with moderate exercise. Oxygen consumption is not similarly increased, indicating that the increase is not related to the metabolic effects of the muscular activity. The findings indicate that the increase in DL with negative pressure breathing is attributable to an increase in the size of the effectively ventilated pulmonary capillary bed.

The increase in Vc during negative pressure breathing must be due, at least in part, to better distribution of perfusion, but it seems certain that previously open capillaries are also being distended, probably as a mechanical consequence of the applied negative pressure. This does not exclude the possibility that alterations in ventilation account for the previously described decrease in arterial oxygen saturation during negative pressure breathing.

\section{References}

1. Krogh, M. The diffusion of gases through the lungs of man. J. Physiol. (Lond.) 1915, 49, 271.

2. Ross, J. C., R. Frayser, and J. B. Hickam. A study of the mechanism by which exercise increases the pulmonary diffusing capacity for carbon monoxide. J. clin. Invest. 1959, 38, 916.

3. Rosenberg, E., and R. E. Forster. Changes in diffusing capacity of isolated cat lungs with blood pressure and flow. J. appl. Physiol. 1960, 15, 883.

4. Duke, H. N., and W. Rouse. Pulmonary diffusing capacity for $\mathrm{CO}$ and hemodynamic changes in isolated perfused cats' lungs. J. appl. Physiol. 1963, 18, 83.

5. Ross, J. C., G. D. Ley, R. F. Coburn, J. L. Eller, and R. E. Forster. Influence of pressure suit inflation on pulmonary diffusing capacity in man. J. appl. Physiol. 1962, 17, 259.

6. Lewis, B. M., R. E. Forster, and E. L. Beckman. Effect of inflation of a pressure suit on pulmonary diffusing capacity in man. J. appl. Physiol. 1958, $12,57$.

7. Lewis, B. M., T.-H. Lin, F. E. Noe, and R. Komisaruk. The measurement of pulmonary capillary blood volume and pulmonary membrane diffusing capacity in normal subjects; the effects of exercise and position. J. clin. Invest. 1958, 37, 1061.

8. Daly, W. J., S. T. Giammona, and J. C. Ross. The "pressure-volume relationship" of the normal pulmonary capillary bed. J. clin. Invest. 1965, 44, 1261.

9. Berry, J. N., H. K. Thompson, Jr., D. E. Miller, and H. D. McIntosh. Changes in cardiac output, stroke volume, and central venous pressure induced by atropine in man. Amer. Heart J. 1959, 58, 204.
10. Gorten, R., J. C. Gunnells, A. M. Weissler, and E. A. Stead, Jr. Effects of atropine and isoproterenol on cardiac output, central venous pressure, and mean transit time of indicators placed at three different sites in the venous system. Circulat. Res. 1961, 9, 979.

11. Daly, W. J., J. C. Ross, and R. H. Behnke. The effect of changes in the pulmonary vascular bed produced by atropine, pulmonary engorgement, and positive-pressure breathing on diffusing and mechanical properties of the lung. J. clin. Invest. 1963, 42, 1083.

12. Cotes, J. E., D. P. Snidal, and R. H. Shepard. Effect of negative intra-alveolar pressure on pulmonary diffusing capacity. J. appl. Physiol. 1960, $15,372$.

13. Steiner, S. H., and R. H. Behnke. Pulmonary venous admixture in man during negative pressure respiration. J. appl. Physiol. 1961, 16, 1047.

14. Watson, J. F., N. S. Cherniack, and F. W. Zechman. Respiratory mechanics during forward acceleration. J. clin. Invest. 1960, 39, 1737.

15. Steiner, S. H., and G. C. E. Mueller. Pulmonary arterial shunting in man during forward acceleration. J. appl. Physiol. 1961, 16, 1081.

16. Zechman, F., and G. Mueller. Effect of forward acceleration and negative pressure breathing on pulmonary diffusion. J. appl. Physiol. 1962, 17, 909.

17. Ogilvie, C. M., R. E. Forster, W. S. Blakemore, and J. W. Morton. A standardized breath-holding technique for the clinical determination of the diffusing capacity of the lung for carbon monoxide. J. clin. Invest. 1957, 36, 1.

18. Daly, W. J., S. T. Giammona, J. C. Ross, and H. Feigenbaum. Effects of pulmonary vascular congestion on postural changes in the perfusion and filling of the pulmonary vascular bed. J. clin. Invest. $1964,43,68$.

19. Roughton, F. J. W., and R. E. Forster. Relative importance of diffusion and chemical reaction rates in determining rate of exchange of gases in the human lung, with special reference to true diffusing capacity of pulmonary membrane and volume of blood in lung capillaries. J. appl. Physiol. 1957, $11,290$.

20. McNeill, R. S., J. Rankin, and R. E. Forster. The diffusing capacity of the pulmonary membrane and the pulmonary capillary blood volume in cardiopulmonary disease. Clin. Sci. 1958, 17, 465.

21. Roughton, F. J. W., R. E. Forster, and L. Cander. Rate at which carbon monoxide replaces oxygen from combination with human hemoglobin in solution and in the red cell. J. appl. Physiol. 1957, 11, 269.

22. Snedecor, G. W., and W. G. Cochran. Statistical Methods Applied to Experiments in Agriculture and Biology, 5th ed. Ames, Iowa, Iowa State University Press, 1956.

23. Johnson, R. L., Jr., W. S. Spicer, J. M. Bishop, and R. E. Forster. Pulmonary capillary blood volume, 
flow and diffusing capacity during exercise. J. appl. Physiol. 1960, 15, 893.

24. Paley, H. W., J. J. Leonard, G. W. N. Eggers, Jr., W. J. DeGroot, and J. V. Warren. Hemodynamic effects of full phase negative pressure breathing (abstract). Circulation 1960, 22, 794.

25. Kilburn, K. H., and H. O. Sieker. Hemodynamic effects of continuous positive and negative pressure breathing in normal man. Circulat. Res. 1960, 8, 660.

26. Ernsting, J. The compliance of the human lungs during positive and negative pressure breathing (abstract). J. Physiol. (Lond.) 1958, 144, 14P.

27. Hubay, C. A., R. C. Waltz, G. A. Brecher, J. Praglin, and R. A. Hingson. Circulatory dynamics of venous return during positive-negative pressure respiration. Anesthesiology 1954, 15, 445.

28. Ross, J. C., T. H. Lord, and G. D. Ley. Effect of pressure-suit inflation on pulmonary-diffusing capacity. J. appl. Physiol. 1960, 15, 843.

29. Ross, J. C., R. W. Reinhart, J. F. Boxell, and L. H. King, Jr. Relationship of increased breath-holding diffusing capacity to ventilation in exercise. J. appl. Physiol. 1963, 18, 794.

30. Lenfant, C., and B. J. Howell. Cardiovascular adjustments in dogs during continuous pressure breathing. J. appl. Physiol. 1960, 15, 425.

31. West, J. B., and C. T. Dollery. Distribution of blood flow and ventilation-perfusion ratio in the lung, measured with radioactive $\mathrm{CO}_{2}$ J. appl. Physiol. 1960, 15, 405.

32. Turino, G. M., M. Brandfonbrener, and A. P. Fishman. The effect of changes in ventilation and pulmonary blood flow on the diffusing capacity of the lung. J. clin. Invest. 1959, 38, 1186.

33. Riley, R. L., S. Permutt, S. Said, M. Godfrey, T. O. Cheng, J. B. L. Howell, and R. H. Shepard. Effect of posture on pulmonary dead space in man. J. appl. Physiol. 1959, 14, 339.

34. West, J. B., and C. T. Dollery. Distribution of blood flow and the pressure-flow relations of the whole lung. J. appl. Physiol. 1965, 20, 175.

35. Burton, A. C. On the physical equilibrium of small blood vessels. Amer. J. Physiol. 1951, 164, 319.

36. Holt, J. P. The effect of positive and negative intrathoracic pressure on cardiac output and venous pressure in the dog. Amer. J. Physiol. 1944, 142, 594.

37. Ting, E. Y., S. K. Hong, and H. Rahn. Cardiovascular responses of man during negative-pressure breathing. J. appl. Physiol. 1960, 15, 557.

38. West, J. B., C. T. Dollery, and A. Naimark. Distribution of blood flow to isolated lung; relation to vascular and alveolar pressures. J. appl. Physiol. 1964, 19, 713.

39. Mostyn, E. M., S. Helle, J. B. L. Gee, L. G. Bentivoglio, and $\mathrm{D}$. V. Bates. Pulmonary diffusing capacity of athletes. J. appl. Physiol. 1963, 18, 687. 